\section{The Role of Some Transcriptional Factors in the Development of the Upper Gastrointestinal Tract}

\author{
Vernygorodskyi Sergii ${ }^{1 *}$ and Rekun Tetyana ${ }^{2}$ \\ ${ }^{1}$ Pathological Anatomy, Forensic Medicine and Law Departments, Vinnytsia \\ National Pirogov Memorial, Medical University, Vinnytsia, Ukraine \\ ${ }^{2}$ Department of Histology, Vinnytsia National Pirogov Memorial, Medical \\ University, Vinnytsia, Ukraine
}

\section{Introduction}

During early embryogenesis, the Gastrointestinal Tract (GIT) develops from two endoderm invaginations at the anterior (Anterior Intestinal Portal, AIP) and posterior (Caudal Intestinal Portal, CIP) ends of the embryo. Several transcription factors are expressed in the early AIP and CIP endoderm and their mutant phenotypes suggest roles in endoderm specification and early patterning. For instance, GATA4 (a member of the GATA family of transcription factors) is expressed very early in the definitive AIP endoderm, FOXA2 (a fork head domain/winged helix transcription factor, previously called HNF $3 \beta$ ) is also expressed in the definitive endoderm. Some members of the Homeobox (HOX) family gene also are expressed in the visceral endoderm $[1,2]$.

Different molecular pathways and transcription factors have been described and studies in the processes of esophagus, stomach and intestine development. Key molecular pathways that involved in Gastrointestinal Tract (GIT) differentiation include the Hedgehog (Hh), Bone Morphogenetic Protein (BMP), and Notch signaling pathways, the HOX and SOX transcription factors, transformation-related protein (p63), the Eph receptors/ephrin ligands (Eph-ephrin) signaling system, the Wnt/ $\beta$-catenin and TCP signaling pathways. Many of these systems are best known as critical control factors in general body plan developmental processes as well as role in organ pattern formation including having key roles in gastrointestinal development [3].

In order to understand better the role of these factors in the upper and lower parts of GIT development, we have decided to choose and investigate CDX2 and p63 expression in epithelia of the lower part of the esophagus (gastroesophageal junction), gastric cardia, small and large intestine.

CDX1 and CDX2 are members of the caudal-related homeobox gene family and are intestine-specific transcriptional factors [4]. In adult mice and humans, expression of CDX1 and CDX2 is strictly confined to the gut, from the duodenum to the rectum [5]. While normal gastric mucosa does not express the transcriptional factors CDX1 and CDX2, aberrant expression of CDX1 and CDX2 is observed in animal and human gastric Intestinal Metaplasia (IM) [6,7].

The human p63 gene is located on chromosome 3q27-29 and comprises 15 exons. Like the other members of the p53 family, p63 is expressed from two different promoters, $\mathrm{P} 1$ and $\mathrm{P} 2$, that generate two classes of proteins, TAp63, which contains the N-terminal Transactivation (TA) domain, and the N-terminal truncated ( Np63) isoform, which lacks this transactivation domain. P63 is a key regulator of the expansion of the basal keratinocyte population and is essential for the development of several different epithelia cellular proliferation, differentiation and survival in both physiological and pathological contexts. Despite accumulating evidence about the p63 network, the molecular mechanisms by which p63 participates in epithelial self-renewal and homeostasis are complex and still far from being fully understood [8]. 
Yaron Daniel et al., indicated that p63 plays a critical role in the development of normal esophageal and tracheobronchial epithelia and appears to control the commitment of early stem cells into basal cell progeny and the maintenance of basal cells [9].

Substantial debate exists about the cells of origin of Barrett's Esophagus (BE) and the underlying molecular mechanisms [10]. Several theories have been proposed, including the trans differentiation of one committed cell type to another or the reprogramming of a progenitor or stem cell population toward a simple epithelial lineage rather than a stratified one [11]. Molecularly, two key players would be p63 and CDX2, the latter being a transcription factor of the caudal-related homeobox family with an important role in intestinal epithelial development and differentiation. Consistent with this view, immunohistopathological and functional experimental studies have implicated the inappropriate expression of CDX2 in BE $[11,12]$. Conversely, conditional CDX2 deletion in the intestine results in squamous metaplasia. Expression of p63 is lost in BE [11,12]. Thus, one attractive hypothesis is that $\mathrm{p} 63$ normally functions as a negative regulator of CDX2 expression. However, now Wang et al. report that CDX2 is not up regulated in esophageal cells lacking p63, in spite of the columnar phenotype of these cells. The authors also note that increased expression of CDX2 is not constantly observed in all forms of BE. This may be a feature of the disease's later steps and/or a reflection of different clinical classifications and heterogeneity of the condition $[11,12]$.

Despite intense research efforts, the molecular mechanisms underlying this metaplastic change in epithelial phenotype have not been completely elucidated.

The identity of the cell that gives rise to BE has not been definitively identified [13]. The esophagus originates from the foregut endoderm during early embryonic development. Its epithelium undergoes a series of changes involving the differentiation of stem cells into unique cell types and ultimately forming the mature epithelia [9]. In the esophageal epithelium, stem cells differentiate first into ciliated cells, followed by basal cells and after that into stratified squamous non-keratinized epithelium but mechanisms of these transformations are still unclear up to now. That's why the purpose of our research was to study the role of p63 in differentiation of the esophageal and GI epithelia, to investigate the expression and significance of caudal-related homeobox transcription factor (CDX2) and to determine whether CDX2 plays an essential role in the differentiation of upper GIT.

\section{Materials and Methods}

The present study included 169 autopsied formalin-fixed human embryos and fetuses with Gestational Age (GA) 4-38 weeks of Caucasian ethnic origin. All autopsies were performed between 4 and 24 $\mathrm{h}$ after death as pre-arranged protocol followed by the department, after a written consent, which included name of the mother, mode of delivery, sex of the fetus, anthropometry, external and internal examination. The presence of congenital malformations involving the GIT was considered as an exclusion criterion. Crown-Rump Length (CRL) was the main criterion for estimating fetal age. The fetal ages are indicated in (Table 1). Routine histology included hematoxylin and eosin staining as well as alcian blue and PAS staining.

\begin{tabular}{|c|c|c|c|c|}
\hline No & Age (weeks) & Number & CRL, мM \\
\hline 1 & $4-5$ & 6 & $6.1 \pm 0.3$ \\
\hline 2 & $6-7$ & 6 & $15.1 \pm 0.6$ \\
\hline 3 & $8-9$ & 7 & $19.4 \pm 0.5$ \\
\hline 4 & $10-11$ & 10 & $39.02 \pm 0.5$ \\
\hline 5 & $12-13$ & 11 & $58.72 \pm 2.27$ \\
\hline 6 & $14-15$ & 12 & $93.11 \pm 5.1$ \\
\hline 7 & $16-17$ & 15 & $122.17 \pm 2.7$ \\
\hline 8 & $18-20$ & 19 & $152.9 \pm 3.5$ \\
\hline 9 & $21-24$ & 20 & $192.14 \pm 1.8$ \\
\hline 10 & $25-28$ & 13 & $230.96 \pm 3.1$ \\
\hline 11 & $29-32$ & 14 & $264.83 \pm 1.7$ \\
\hline & 12 & $33-36$ & 20 & $302.92 \pm 1.4$ \\
\hline 13 & $37-38$ & 16 & $341.5 \pm 5.7$ \\
\hline
\end{tabular}

Histochemistry Serial sections, $4 \mu \mathrm{m}$ thick, were cut from each sample, and stained by the following: haematoxylin and eosin, $\mathrm{AB} \mathrm{pH}$ 2.5-PAS to differentiate acid from neutral mucins, Gomori's aldehyde fuchsin/AB $\mathrm{pH} 2.5$ to differentiate sulphomucins from sialomucins (Table 2). The results were expressed semi quantitatively for each histological group as the number of sections positively stained, the predominant cell type labeled, and the average score of the positively labeled cells. The extent of staining for each mucins, was scored according to the number of cytoplasmic and luminal stained carcinoma cells in 100 tumor cells. Less than 5\% positive cells were accepted as negative, while $\geq 5 \%$ positive cells were accepted as positive.

\begin{tabular}{|c|c|c|}
\hline & AB-PAS & AF-AB \\
\hline Neutral mucins & Magenta & 0 \\
\hline Sialomucins & Blue & Blue \\
\hline Sulphomucins & Blue & Purple \\
\hline
\end{tabular}

Table 1: Histochemical techniques used to characterise mucins.

Note: $0=$ negative staining, $\mathrm{PAS}=$ Periodic Acid Schiff, $\mathrm{AB}=$ Alcian Blue, $\mathrm{AF}=$ Aldehyde Fuchsin

Immunohistochemical studies were conducted in paraffin sections using the streptavidin biotin visualization method (Dako, Denmark). Antigen demasking was carried out in citrate buffer at $\mathrm{pH}$ 6.0. As initial antibodies we used mouse and rabbit monoclonal antibodies. Cell nuclei were counterstained with Mayer hematoxylin during 15$60 \mathrm{~s}$. Gene expression of transcription factor of intestinal differentiation CDX2 was estimated with the use of mouse monoclonal antigens to nucleus antigen CDX2 (clone DAK-CDX2, Dako, Denmark) and p63 Clone DAK-p63. In preparations at 400-fold microscope enlargement, we determined the intestinal differentiation index (nucleus mark CDX2 and p63) in five accidentally selected fields of vision ( $\leq$ 500 cells) as a portion in percentage of positively stained nuclei of epithelial cells of the esophagus, stomach and intestine. CDX2 was evaluated immunohistochemically using anti-CDX2 antibody. 
All patients were thoroughly informed about the study that was approved by the local ethics committee statistical analysis. Results of immunohistochemical alterations were compared to the clinic-pathologic features using chi-square test with two tailed $\mathrm{p}$ value, $\mathrm{p}<0.05$ was considered as significant.

\section{Results and Discussion}

In embryos with crown-rump length (CRL) $6.1 \pm 0.3 \mathrm{~mm}$ (4-5 gestation weeks) and $15.1 \pm 0.6 \mathrm{~mm}$ (6-7 gestation weeks) esophageal epithelium consists of a layer of two to three cells and the deepest layer is formed by columnar cells with strongly positive reaction for p63 in nuclei that were located on different levels (Figure 1).

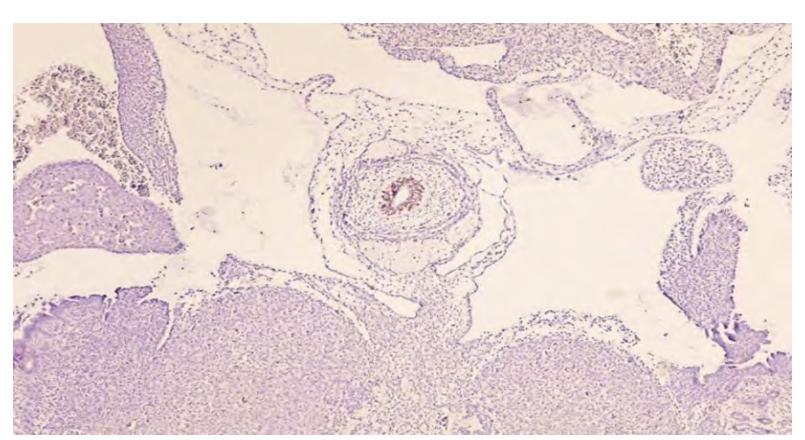

Figure 1: An intense nuclear staining of p63 in nuclei of the esophagus columnar epithelium. Embryo esophagus, 5 weeks. Immunohistochemistry of anti-p63, 200X.

In positive cases, the immunoreactivity was predominantly nuclear with occasional faint cytoplasmic staining. Columnar cells were with basophilic cytoplasm and scant cytoplasm that contains predominantly neutral mucins $(4.85 \pm 0.31 \%)$ without sulfomucins and small amount of acid mucins (Tables $3 \& 4$ ).

\begin{tabular}{|c|c|c|c|c|}
\hline No & Age (weeks) & AM (\%) & NM (\%) & SM (\%) \\
\hline 1 & $4-5$ & $0.74 \pm 0.05$ & $4.85 \pm 0.31$ & - \\
\hline 2 & $6-7$ & $0.94 \pm 0.05$ & $5.18 \pm 0.3$ & - \\
\hline 3 & $8-9$ & $0.70 \pm 0.01$ & $6.18 \pm 0.15$ & - \\
\hline 4 & $10-11$ & $0.40 \pm 0.01$ & $5.95 \pm 0.15$ & - \\
\hline 5 & $12-13$ & - & $4.95 \pm 0.2$ & - \\
\hline 6 & $14-15$ & - & $5.6 \pm 0.09$ & - \\
\hline 7 & $16-17$ & - & $7.65 \pm 0.18$ & - \\
\hline 8 & $18-20$ & $4.63 \pm 0.008$ & $4.6 \pm 0.09$ & - \\
\hline 9 & $21-24$ & $5.8 \pm 0.10$ & $7.45 \pm 0.009$ & - \\
\hline 10 & $25-28$ & $2.4 \pm 0.10$ & $7.94 \pm 0.08$ & $1.96 \pm 0.3$ \\
\hline 11 & $29-32$ & $2.1 \pm 0.1$ & $2.15 \pm 11$ & $2.18 \pm 0.34-$ \\
\hline 12 & $33-36$ & $0.36 \pm 0.07$ & $1.65 \pm 0.13$ & $1.4 \pm 0.2-$ \\
\hline 13 & $37-38$ & $0.24 \pm 0.01$ & $1.02 \pm 0.03$ & $0.93 \pm 0.12-$ \\
\hline
\end{tabular}

Table 3: Content of mucins in esophageal cells according to the phase image analysis data based on $0.01 \mathrm{~mm}^{2}$.

Note: AM-Acid Mucins, NM-Neutral Mucins, SM-Sulfomucins, -absence of mucins.

By the eighth week (CRL 19.4 $\pm 0.5 \mathrm{~mm}$ ), the epithelium remains pseudostratified with the appearance of single vacuoles in the cells cytoplasm. However, already in the ninth week, the vacuoles reach their largest volumes. After the tenth week (CRL 37-38 mm), a pseudostratified epithelium starts to get considerably thinner, and starting with CRL $40 \mathrm{~mm}$ becomes ciliated multilayered columnar. Starting from this period the nuclei become negative for p63 labeling up to the sixteenth week, when squamous epithelium arises in the lower part of the esophagus and columnar epithelium of the stomach cardia part becomes more differentiated but we are not revealed expression of p63 in the latter. It was interesting that positive expression of CDX2 was observed only in small and large epithelium from the sixteenth week. The positive weak expression of p63 was detected in the esophageal cells by the 25 week. From 25 to 38 gestation weeks, the progressing increase of $\mathrm{p} 63$ expressing is observed in nuclei of esophageal epitheliocytes. In contrast with esophageal epithelium p63 expression was not found in the gastric and intestinal mucosa during all the time of investigation (Figure 2).

\begin{tabular}{|c|c|c|c|c|}
\hline No & Age (weeks) & AM (\%) & NM (\%) & SM (\%) \\
\hline 1 & $4-5$ & $1.69 \pm 0.23$ & $4.4 \pm 0.29$ & - \\
\hline 2 & $6-7$ & $3.0 \pm 0.19$ & $5.3 \pm 0.21$ & $0.39 \pm 0.04$ \\
\hline 3 & $8-9$ & $3.8 \pm 0.08$ & $6.2 \pm 0.08$ & $0.53 \pm 0.06$ \\
\hline 4 & $10-11$ & $4.05 \pm 0.09$ & $5.95 \pm 0.09$ & - \\
\hline 5 & $12-13$ & $6.6 \pm 0.11$ & $6 \pm 0.1$ & - \\
\hline 6 & $14-15$ & $8.1 \pm 0.11$ & $6.9 \pm 0.10$ & - \\
\hline 7 & $16-17$ & $15.9 \pm 0.10$ & $37 \pm 0.4$ & $3.98 \pm 0.28$ \\
\hline 8 & $18-20$ & $17 \pm 0.12$ & $21.9 \pm 0.13$ & $2.9 \pm 0.24$ \\
\hline 9 & $21-24$ & $24.5 \pm 0.13$ & $20.6 \pm 0.13$ & $0.47 \pm 0.06$ \\
\hline 10 & $25-28$ & $14 \pm 0.09$ & $19 \pm 0.10$ & - \\
\hline 11 & $29-32$ & $5.23 \pm 0.01$ & $29.9 \pm 0.11$ & - \\
\hline 12 & $33-36$ & $1.75 \pm 0.13$ & $17.4 \pm 0.13$ & - \\
\hline 13 & $37-38$ & $0.94 \pm 0.05$ & $20 \pm 0.11$ & - \\
\hline
\end{tabular}

Table 4: Content of mucins in cardiac cells according to the phase image analysis data based on $0.01 \mathrm{~mm}^{2}$.

Note: AM-Acid Mucins, NM-Neutral Mucins, SM-Sulfomucins, -absence of mucins.

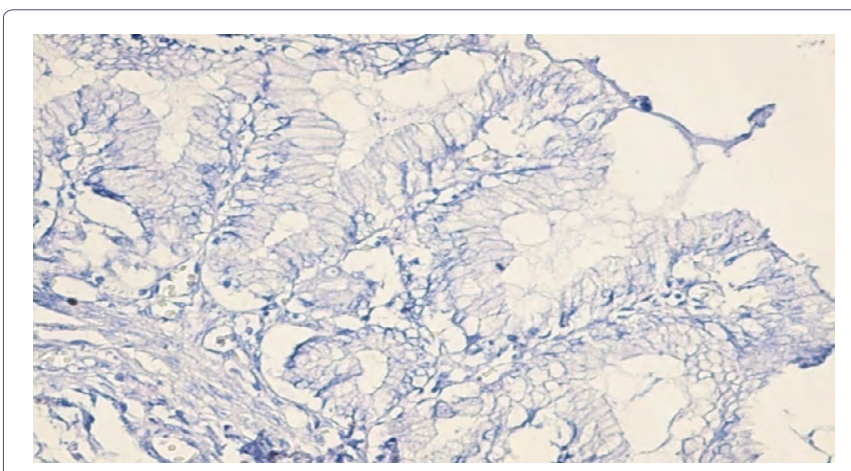

Figure 2: A negative nuclear staining of p63 in nuclei of the gastric columnar epithelium. Fetal gastric mucosa, 28 weeks. Immunohistochemistry of anti-p63, 400X.

In small and large intestine CDX2 expression was detected in nuclei of columnar epithelium beginning from 16 gestational weeks till 38 weeks and did not express in early embryonic and fetal period 
(from 4 to 15 weeks). After 16 gestational weeks the nuclei of small intestinal epithelia are CDX2 positive in the majority of cases, usually showing a strong, uniform staining (Figure 3). Moderate nuclear staining was observed extensively in large intestinal epithelium (Figure 4).

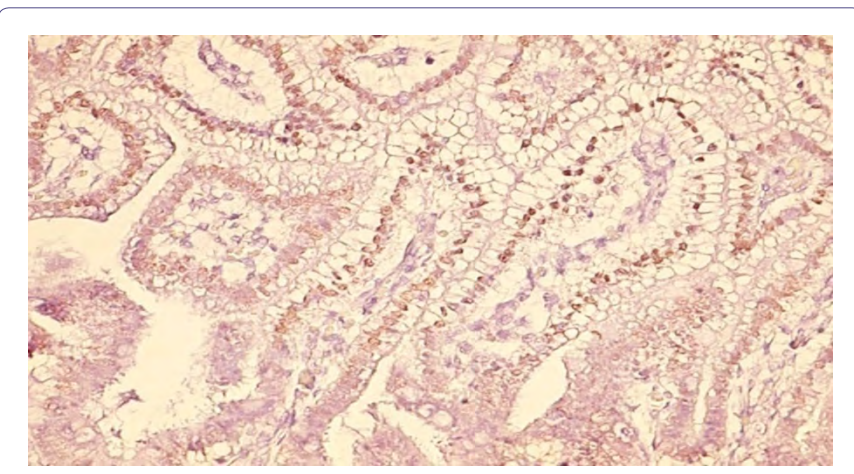

Figure 3: A strong expression of CDX2 in nuclei of the small intestine columnar cells mucosa. Fetal small intestine, 16 weeks. Immunohistochemistry of anti-CDX2, 200X.

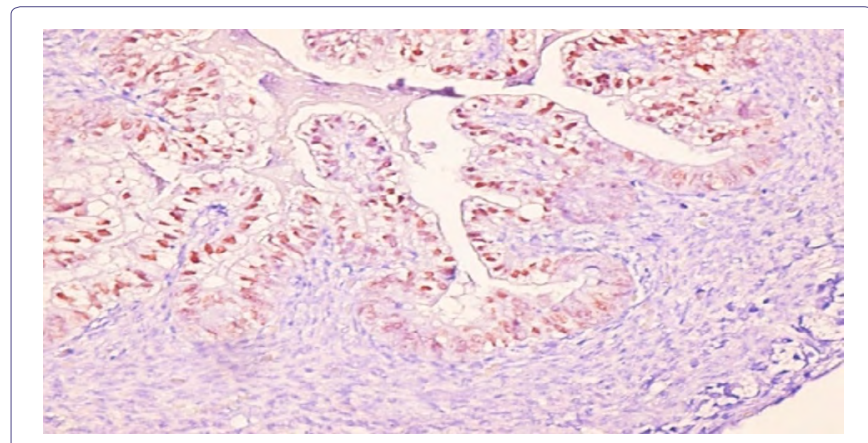

Figure 4: A moderate expression of CDX2 in nuclei of the large intestine. Fetal large intestine, 16 weeks. Immunohistochemistry of anti-CDX2, 200X.

It is necessary to note that after 16 weeks small and large intestinal epithelia are CDX2 positive in the large majority of cases, usually showing a moderate staining of nuclei with focal staining are included, about 160 of cases $(95 \%)$. The fine granular cytoplasmic staining was also observed in the perinuclear regions that were PAS and alcian blue positive (Figures 5 and 6). When in early embryonic and fetal period (from 4 to 16 weeks) the expression is more often negative in 165 of 169 cases $(98 \%)$. In compare with intestine CDX2 has not been expressed in normal esophageal or gastric mucosa during the study period.

GIT development may be divided in multiple stages, where the number and type of epithelial cells are sequentially determined. There is different molecular signaling that regulates GIT development and it is possible to observe that the molecular signals are expressed in different stages of embryogenesis. Starting from the $8^{\text {th }}$ week of gestation, the esophageal epithelium is gradually replaced by a ciliated and then a squamous epithelium until a non-keratinized stratified squamous epithelium is fully developed.

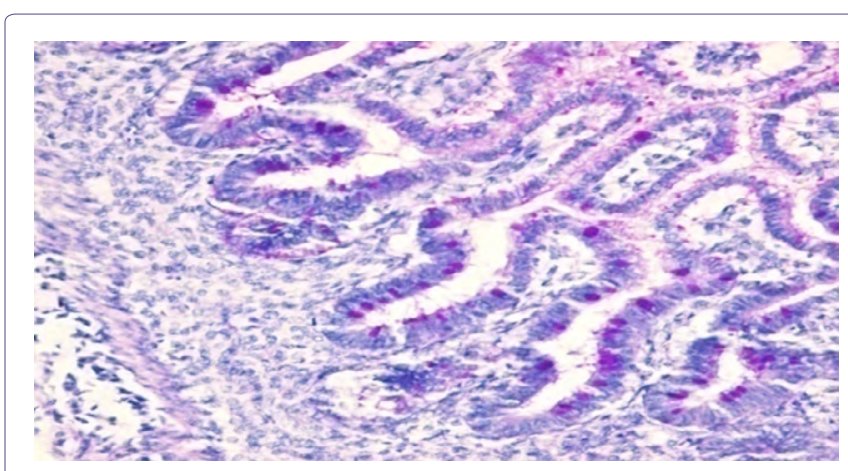

Figure 5: A moderate expression of neutral mucins in cytoplasm of goblet cell and brush border of the small intestine. Fetal small intestine, 12 weeks. Histochemistry. PAS - reaction, 400X.

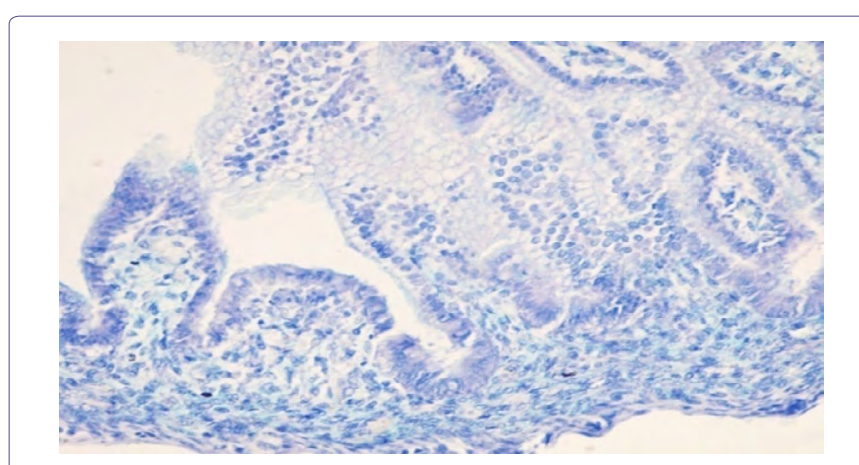

Figure 6: A weak focal expression of acid mucins in cytoplasm of columnar cells and brush border of the small intestine. Fetal small intestine, 12 weeks. Histochemistry. Alcian blue, $400 \mathrm{X}$

Given that the normal epithelium found in the human esophagus after birth is predominantly squamous (the exception being the epithelium lining submucosal gland ducts and comprising the submucosal glands), two distinct hypotheses developed on how a squamous epithelial cell could give rise to a columnar epithelial cell. First, a fully differentiated squamous epithelial cell could undergo irreversible direct phenotypic conversion through molecular reprogramming into an intestinalized columnar cell without undergoing mitosis, a process termed transdifferentiation. Alternatively, a squamous epithelial precursor or stem cell could undergo molecular reprogramming leading to a change in the cell fate of progeny cells, a process termed transcommitment [14]. The other potential source for the BE cell of origin besides a proximally migrating columnar epithelial cell, a native squamous epithelial cell, or a native epithelial cell from an esophageal submucosal gland or duct, is an external circulating stem cell (i.e., from the bone marrow). Potential sources for the cell or tissue of origin for metaplastic Barrett's epithelium are reviewed including native esophageal differentiated squamous cells, progenitor cells native to the esophagus located within the squamous epithelium or in the submucosal glands or ducts, circulating bone marrow-derived stem cells, and columnar progenitor cells from the squamocolumnar junction or the gastric cardia that proximally shift into the esophagus to fill voids left by damaged squamous epithelium [15]. The conversion of stratified squamous esophageal epithelium may require an intermediate columnar step and may arise via reprogramming of the differentiation 
program of basal cells, from the glandular ducts, or from cells at the gastroesophageal junction in order for CDX2 to induce IM. Perhaps, these cell lines do not contain the requisite squamous progenitor or stem cell with the plasticity to become an intestinalized columnar cell. The acquisition of a non-intestinal columnar phenotype could be compared to the cardia-type mucosa that has been proposed as an intermediate in BM. The phenotype switching from squamous to intestinalized columnar may require multiple genetic alterations in a specific combination and sequence. To date, the majority of studies perhaps are to stably express a columnar transcription factor followed by an intestinal transcription factor followed by a mucus-related transcription factor [16].

The various lines of evidence suggest the presence of multiple stem cell pools in the stomach epithelium, but the relationships between these populations and their respective properties and developmental origins remain obscure [17].

In our research CDX-2 is not demonstrable immunohistochemically in the esophageal or gastric cells of the GIT at any stage of maturation. CDX2 expression was highly restricted to the small and large intestinal epithelia in mid-and late gestation. Our investigations coincide with Y. Daniely et al., which demonstrated that lack of p63 expression results in the development of a highly ordered, columnar ciliated epithelium deficient in basal cells, but our data do not concur with $\mathrm{X}$. Wang et al., $[9,13]$. Which proposed that the metaplasia derives from a reservoir of progenitor cells, which pre-exist in embryonic tissue and then repopulate or "take over" a damaged area when other cell populations have left.

Morphogenesis occurs by numerous genetic and epigenetic factors not just by a single gene and also most of the developmental defects in GIT usually occur as a result of mutations in genes encoding signaling molecules and transcriptional factors. Clearly we still have very limited insight in pathways and genes involved in normal homeostasis of the esophageal epithelium.

The present results suggest that CDX2 is a key regulator for the development and differentiation of columnar epithelium in small and large intestine in mid and late stages of embryogenesis. We didn't find an ectopic expression of CDX2 in the gastric or esophageal epithelium. Our investigation has shown that $\mathrm{p} 63$ protein is essential for the morphogenesis and differentiation of esophageal epithelium. The esophageal squamous epithelium contains only one type of cell which differentiates along one lineage and expresses transcription factors that are absent from the stomach, such as p63.

In this study, we have used immunohistochemistry to characterize the patterns of CDX2 and p63 expression in normal esophageal, gastric and intestinal mucosa. Our hypothesis is that $\mathrm{p} 63$ may exert essential roles in regulating the switch between different types of intercellular contacts that are necessary for the formation, maintenance, differentiation and renewal of esophageal epithelium.

\section{References}

1. Roberts DJ, Johnson RL, Burke AC, Nelson CE, Morgan BA, et al. (1995) Sonic hedgehog is an endodermal signal inducing Bmp-4 and Hox genes during induction and regionalization of the chick hindgut. Development 121: 3163-3174.

2. Le Guen L, Marchal S, Faure S, de Santa Barbara P (2015) Mesenchymal-epithelial interactions during digestive tract development and epithelial stem cell regeneration. Cell Mol Life Sci 72: 3883-3896.

3. de Santa Barbara P, van den Brink GR, Roberts DJ (2003) Development and differentiation of the intestinal epithelium. Cell Mol Life Sci 60: 13221332.

4. Silberg DG, Swain GP, Suh ER, Traber PG (2000) CDX1 and CDX2 expression during intestinal development. Gastroenterology 119: 961-971.

5. Kang JM, Lee BH, Kim N, Lee HS, Lee HE, et al. (2011) CDX1 and CDX2 Expression in Intestinal Metaplasia, Dysplasia and Gastric Cancer. J Korean Med Sci 26: 647-653.

6. Satoh K, Mutoh H, Eda A, Yanaka I, Osawa H, et al. (2002) Aberrant expression of CDX2 in the gastric mucosa with and without intestinal metaplasia: effect of eradication of Helicobacter pylori. Helicobacter 7: 192-198.

7. Vernygorodskyi SV, Degtiariova LV, Iatsyna OI, Blume YB, Yemets AI (2015) [Role of transcription factors in transdifferentiation of the gastric mucosa]. Tsitol Genet 49: 42-47.

8. Candi E, Cipollone R, Rivetti di Val Cervo P, Gonfloni S, Melino G, et al. (2008) p63 in epithelial development. Cell Mol Life Sci 65: 3126-3133.

9. Daniely Y, Liao G, Dixon D, Linnoila RI, Lori A, et al. (2004) Critical role of p63 in the development of a normal esophageal and tracheobronchial epithelium. Am J Physiol Cell Physiol. 287: 171-181.

10. Lefort K, Dotto GP (2011) p63 and epithelial metaplasia: a gutsy choice. Cell 145: 1003-1005.

11. Quinlan JM, Colleypriest BJ, Farrant M, Tosh D (2007) Epithelial metaplasia and the development of cancer. Biochimica et Biophysica Acta 1776: 10-21.

12. Herfs M, Hubert P, Delvenne P (2009) Epithelial metaplasia: adult stem cell reprogramming and (pre)neoplastic transformation mediated by inflammation? Trends Mol Med 15: 245-253.

13. Wang X, Ouyang H, Yamamoto Y, Kumar PA, Wei TS, et al. (2011) Residual embryonic cells as precursors of a Barrett's-like metaplasia. Cell 145: 1023-1035.

14. Wang DH (2017) The Esophageal Squamous Epithelial Cell-Still a Reasonable Candidate for the Barrett's Esophagus Cell of Origin? Cellular and Molecular Gastroenterology and Hepatology 4: 157-160.

15. Wang DH, Souza RF (2016) Transcommitment: Paving the Way to Barrett's Metaplasia. Adv Exp Med Biol 908: 183-212.

16. Mills JC, Sansom OJ (2015) Reserve stem cells: Differentiated cells reprogram to fuel repair, metaplasia, and neoplasia in the adult gastrointestinal tract. Sci Signal 8(385): re8.

17. Kim TH, Shivdasani RA (2016) Stomach development, stem cells and disease. Development 143: 554-565. 


\section{Hit \\ HERALD}

Journal of Anesthesia \& Clinical Care

Journal of Addiction \& Addictive Disorders

Advances in Microbiology Research

Advances in Industrial Biotechnology

Journal of Agronomy \& Agricultural Science

Journal of AIDS Clinical Research \& STDs

Journal of Alcoholism, Drug Abuse \& Substance Dependence

Journal of Allergy Disorders \& Therapy

Journal of Alternative, Complementary \& Integrative Medicine

Journal of Alzheimer's \& Neurodegenerative Diseases

Journal of Angiology \& Vascular Surgery

Journal of Animal Research \& Veterinary Science

Archives of Zoological Studies

Archives of Urology

Journal of Atmospheric \& Earth-Sciences

Journal of Aquaculture \& Fisheries

Journal of Biotech Research \& Biochemistry

Journal of Brain \& Neuroscience Research

Journal of Cancer Biology \& Treatment

Journal of Cardiology \& Neurocardiovascular Diseases

Journal of Cell Biology \& Cell Metabolism

Journal of Clinical Dermatology \& Therapy

Journal of Clinical Immunology \& Immunotherapy

Journal of Clinical Studies \& Medical Case Reports

Journal of Community Medicine \& Public Health Care

Current Trends: Medical \& Biological Engineering

Journal of Cytology \& Tissue Biology

Journal of Dentistry: Oral Health \& Cosmesis

Journal of Diabetes \& Metabolic Disorders

Journal of Dairy Research \& Technology

Journal of Emergency Medicine Trauma \& Surgical Care

Journal of Environmental Science: Current Research

Journal of Food Science \& Nutrition

Journal of Forensic, Legal \& Investigative Sciences

Journal of Gastroenterology \& Hepatology Research
Journal of Gerontology \& Geriatric Medicine

Journal of Genetics \& Genomic Sciences

Journal of Hematology, Blood Transfusion \& Disorders

Journal of Human Endocrinology

Journal of Hospice \& Palliative Medical Care

Journal of Internal Medicine \& Primary Healthcare

Journal of Infectious \& Non Infectious Diseases

Journal of Light \& Laser: Current Trends

Journal of Modern Chemical Sciences

Journal of Medicine: Study \& Research

Journal of Nanotechnology: Nanomedicine \& Nanobiotechnology Journal of Neonatology \& Clinical Pediatrics

Journal of Nephrology \& Renal Therapy

Journal of Non Invasive Vascular Investigation

Journal of Nuclear Medicine, Radiology \& Radiation Therapy

Journal of Obesity \& Weight Loss

Journal of Orthopedic Research \& Physiotherapy

Journal of Otolaryngology, Head \& Neck Surgery

Journal of Protein Research \& Bioinformatics

Journal of Pathology Clinical \& Medical Research

Journal of Pharmacology, Pharmaceutics \& Pharmacovigilance

Journal of Physical Medicine, Rehabilitation \& Disabilities

Journal of Plant Science: Current Research

Journal of Psychiatry, Depression \& Anxiety

Journal of Pulmonary Medicine \& Respiratory Research

Journal of Practical \& Professional Nursing

Journal of Reproductive Medicine, Gynaecology \& Obstetrics

Journal of Stem Cells Research, Development \& Therapy

Journal of Surgery: Current Trends \& Innovations

Journal of Toxicology: Current Research

Journal of Translational Science and Research

Trends in Anatomy \& Physiology

Journal of Vaccines Research \& Vaccination

Journal of Virology \& Antivirals

Submit Your Manuscript: http://www.heraldopenaccess.us/Online-Submission.php 